BMJ Open Sport \& Exercise Medicine

\section{Implementation of a behavioural change intervention to enhance oral health behaviours in elite athletes: a feasibility study}

To cite: Gallagher J, Ashley P, Needleman I. Implementation of a behavioural change intervention to enhance oral health behaviours in elite athletes: a feasibility study. $B M J$ Open Sport \& Exercise Medicine 2020;6: 0000759 . doi:10.1136/ bmjsem-2020-000759

Accepted 19 May 2020

\section{Check for updates}

(c) Author(s) (or their employer(s)) 2020. Re-use permitted under CC BY-NC. No commercial re-use. See rights and permissions. Published by BMJ.

Centre for Oral Health and Performance, University College London, Eastman Dental Institute, London, UK

Correspondence to Professor lan Needleman; i.needleman@ucl.ac.uk

\section{ABSTRACT}

Background Poor oral health of elite athletes is common and is associated with negative performance impacts. There is a need for oral health promotion strategies that are effective within the elite sport environment.

Aim To develop, implement and evaluate a pragmatic oral health promotion intervention that integrated the capability, opportunity, motivation and behaviour model of behavioural change into the knowledge transfer system for effective implementation of preventive interventions.

Methods Repeated measures study. Athletes and support team together viewed one 10 min presentation and three $90 \mathrm{~s}$ information films. Athletes alone received oral health screening, personalised advice and an oral health toolkit. Outcome measures included: (1) oral health knowledge, athlete-reported performance impacts (0slo Sports Trauma Research Centre, OSTRC score), use of oral hygiene aids, gingival inflammation (bleeding) score, recorded at baseline, 4-6 weeks and 12-16 weeks and (2) athlete feedback.

Results We recruited 62 athletes; 44 (71\%) male and 58 (93.5\%) white British, 55 (88.7\%) athletes completed the study. Mean knowledge score improved from 5.69 (1.59) to 6.93 (1.32) $p<0.001$. Mean OSTRC score reduced from $8.73(14.54)$ to $2.73(11.31) p<0.001$. Athlete use of prescription strength fluoride toothpaste increased from $8(12.9 \%)$ to $45(80.4 \%) p<0.001$. Athlete-reported use of interdental cleaning aids at least $2-3 x$ week increased from $10(16.2 \%)$ to $21(34 \%) p=0.013$. Bleeding score remained unchanged.

Conclusion This behavioural change intervention was successfully implemented within different elite sport environments. It was associated with an increase in athlete oral health knowledge, enhanced oral health behaviour, a reduction in self-reported performance impacts and high participant retention.

\section{INTRODUCTION}

A recent study involving 352 elite athletes found dental caries in $49 \%$, gingival inflammation in $77 \%$ and evidence of periodontitis in a further 22\%. ${ }^{1}$ Furthermore, oral health problems make a negative contribution to elite athlete health, well-being and performance. ${ }^{1-3}$ Elite athletes have indicated that

\section{What are the new findings?}

- Addition of the capability, opportunity, motivation and behaviour (COM-B) behavioural change model to the knowledge transfer system can promote athlete adherence to recommended health behaviours.

- This intervention, based on the COM-B behavioura change model, was associated with improvements in oral health knowledge, oral health behaviours and impacts on performance reported by elite athletes.

- Oral health screening and oral health promotion programmes can be implemented in elite athlete teams.

they are willing to adopt enhanced oral health behaviours to improve their oral health. ${ }^{4}$ The document 'Delivering better oral health: a toolkit for prevention, ${ }^{, 5}$ provides evidencebased guidance to support oral health promotion and prevention of common oral diseases. However, the evidence currently relates to the environment outside of sport, therefore, implementation in an elite athlete environment needs to be tested.

To be fully effective, promotion of health should be both targeted and underpinned by scientific evidence. ${ }^{6}$ The knowledge transfer system (KTS) was developed to guide implementation of injury preventive interventions in sport. ${ }^{7}$ The focus of the International Olympic Committee (IOC) consensus statement on prevention of non-communicable diseases is on simple interventions that include behavioural change, designed with an understanding of individual preferences and engagement across relevant networks. ${ }^{8}$ The behavioural change wheel (BCW) provides a structured approach to designing behavioural change interventions and strategies. ${ }^{9}$ At the centre of the wheel is the COM-B model of behaviour that identifies sources of behaviour that could provide opportunities for intervention. ${ }^{10}$ 
Table 1 Behavioural change wheel (BCW) activities

\begin{tabular}{|c|c|}
\hline BCW activity & As it relates to the behaviour of elite athletes \\
\hline $\begin{array}{l}\text { 1. Behavioural target specification: Identify the precise goal of the } \\
\text { intervention in terms of what behaviour/s need/s to change, to what degree, } \\
\text { in what way, and in whom. }\end{array}$ & $\begin{array}{l}\text { Effective disruption of plaque on a daily basis, with } \\
\text { prescription fluoride toothpaste (PFT). }\end{array}$ \\
\hline $\begin{array}{l}\text { 2. Behavioural diagnosis: Find out what would need to change for the } \\
\text { behaviour to change in terms of Capability (physical and psychological), } \\
\text { Opportunity (physical and social) and/or motivation (reflective and } \\
\text { automatic) in the target population, group or individual. }\end{array}$ & $\begin{array}{l}\text { Capability to disrupt plaque effectively and increase } \\
\text { fluoride availability twice daily. } \\
\text { Opportunity to use oral hygiene aids and fluoride } \\
\text { toothpaste. } \\
\text { Motivation to avoid oral health problems and associated } \\
\text { performance impacts. }\end{array}$ \\
\hline $\begin{array}{l}\text { 3. Intervention strategy selection: Use the behavioural diagnosis to decide } \\
\text { what 'intervention functions' to apply: education, persuasion, incentivisation, } \\
\text { coercion, training, restriction, environmental restructuring, modelling, } \\
\text { enablement. }\end{array}$ & $\begin{array}{l}\text { Training and education (Capability). } \\
\text { Modelling, incentivisation, (Opportunity). } \\
\text { Persuasion (Motivation). }\end{array}$ \\
\hline
\end{tabular}

4. Implementation strategy selection: Choose from among a range of policy Service provision: oral health screening. options to support long-term implementation: fiscal policy, legislation, regulation, environmental planning, communications, service provision, guidelines development.

\begin{tabular}{|c|c|}
\hline $\begin{array}{l}\text { 5. Selection of specific behavioural change techniques: Develop a detailed } \\
\text { intervention plan by selecting from among a range of specific behavioural } \\
\text { change techniques (elementary components of interventions such as goal- } \\
\text { setting, providing rewards, etc). }\end{array}$ & $\begin{array}{l}\text { Goal-setting: to brush for } 2 \text { min twice daily with PFT. } \\
\text { Planning: to brush before bed and before training in the } \\
\text { morning. }\end{array}$ \\
\hline
\end{tabular}

- Capability $(\mathrm{C})$, that is, the person having the physical skills and knowledge to perform the behaviour.

- Opportunity $(\mathrm{O})$, that is, access to the necessary materials and social environment such that the person feels able to undertake the new behaviour.

- Motivation (M) refers to a person deciding to adopt the behaviour.

Our aim was to test the feasibility and evaluate the effectiveness of simple preventive interventions, based on the contemporary (COM-B) behavioural change model, to improve oral health knowledge, enhance oral health behaviour and reduce performance impacts, in elite athletes.

\section{METHODS}

\section{Patient and public involvement statement}

We designed the intervention and study protocol with input from experts and an elite athlete focus group. We have provided a final report to each team.

\section{Development of the intervention}

Table 1 presents a summary of the BCW activities that we followed to develop the intervention. ${ }^{9}$

The most important behavioural factor to mitigate the risks, of both dental caries and periodontal diseases, is routinely performed oral hygiene with fluoride. ${ }^{11}$ Where caries risk is increased, high strength prescription fluoride toothpaste (PFT) is indicated. ${ }^{5}$ Therefore, we identified two key target behaviours as effective plaque removal, including interdentally and increasing fluoride availability with PFT 2600 ppm. Two key motivations for change were emphasised:

1. Performance enhancement: poor oral health impairs performance.

2. Appearance: poor oral health can affect appearance.

Thus, oral health was not necessarily the end goal but an approach to achieving high value motivators.

\section{The final intervention}

The final intervention was on two levels: level 1-athletes and support team together viewed one $10 \mathrm{~min}$ presentation focused on building motivation to improve oral health, and three $90 \mathrm{~s}$ information films focused on increasing oral health knowledge and skills to perform optimum oral health behaviour. Level 2-athletes alone received oral health screening, personalised advice and an oral health toolkit containing a manual toothbrush (GlaxoSmithKline (GSK), Sensodyne 3.5), PFT 2800 (Colgate Duraphat) and flosspicks (Procter \& Gamble, Oral B Glide) to enhance COM.

\section{Study design and setting}

We conducted this pragmatic, repeated measures study at the training venues of one professional and two olympic athlete teams. Participation in the study was entirely voluntary and with no obligation and we obtained Informed written consent from each athlete. The study ran for three field periods of July-October 2018, August-December 2018 and February-April 2019 and we collected data at four time points: 


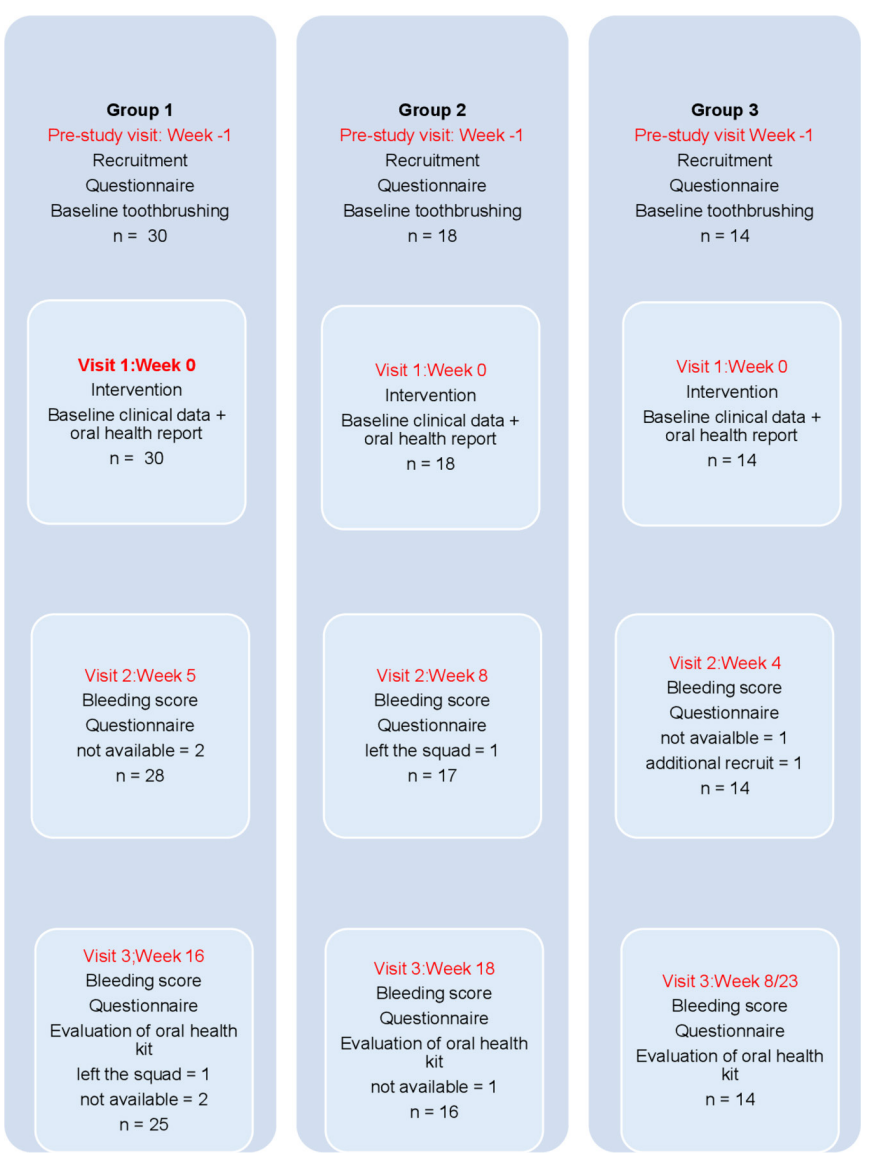

Figure 1 Study flow diagram.

\section{Prestudy visit ( -1 week):}

- Gain participant consent.

- Collect baseline questionnaire data.

2. Study visit 1 (intervention):

- Presentation to the whole team including athletes and medical support staff.

- Oral health screening, clinical assessment of gingival health, provision of oral health report and oral health kit to athletes.

- Athlete evaluation of the presentations and films.

3. Study visit 2 (4-8 weeks):

- Collect follow-up questionnaire data.

- Clinical assessment of gingival health.

4. Study visit 3 (12-18 weeks):

- Collect follow-up questionnaire data.

- Clinical assessment of gingival health.

- Athlete evaluation of the oral health kit.

\section{Outcome measures}

The primary outcomes were: (1) athlete oral health knowledge, oral health behaviours, athlete-reported performance impacts. We measured knowledge with a questionnaire previously used in a study to assess oral health knowledge between dental healthcare professionals and the public. ${ }^{12}$ This questionnaire comprised eight questions with options of true, false or do not know. Each correct answer scored 1, therefore, the maximum possible score was 8 . We asked the athletes about their use of toothbrush, fluoride toothpaste and interdental cleaning aids with items from a questionnaire used in a previous study. ${ }^{4}$ We used an oral health modification of the Oslo Sports Trauma Research Centre (OSTRC) overuse injury questionnaire ${ }^{13}$ (maximum possible score 100 ) to measure impact on performance in sport. ${ }^{1414}$

Secondary outcomes included: gingival inflammation as a short term, objective measure of oral health, athlete evaluation of the presentation and the oral health kit and adherence to toothbrushing measured using a remote sensor, 'Brushlink'. Gingival inflammation (bleeding) was measured as a bleeding on probing percentage score (maximum possible score 100\%).

Baseline oral health was measured during oral health screening with standard clinical indices of dental caries, periodontal health and erosive tooth wear, as described in a previous paper. ${ }^{1}$ The same dentist administered the questionnaires, delivered the intervention and conducted the clinical measurements at each study visit.

\section{Sample size and statistical analysis}

As this was an exploratory study, we did not calculate a minimum sample size. However, for studies using selfreported outcome measures, an acceptable minimum sample size is generally considered to be $50,{ }^{15}$ therefore, we aimed to recruit 55 athletes to allow for a drop-out rate of $10 \%$. Data were coded for entry into a spreadsheet by a person independent of the study then imported to a standard statistical package (IBM SPSS Statistics for Windows, V.22.0) for analysis. Distribution of the data was assessed and continuous variables described as median with IQR and range. Counts and percentages summarise the categorical data. Non-parametric tests included the $\mathrm{X}^{2}$ for categorical data and the Wilcoxon signed-rank test for continuous data. Significance values for all hypothesis tests were set at 0.05 .

\section{RESULTS}

We delivered the intervention to 62 athletes and 55 $(88.7 \%)$ completed the study. Figure 1 presents the flow of participants, with the reasons why seven athletes did not complete the study.

\section{Characteristics of the group}

Table 2 provides a summary of the demographics and baseline oral health of the group. Thirty $(48.4 \%)$ were professional athletes and $32(51.6 \%)$ were from Olympic training squads.

\section{Primary outcomes}

Table 3 provides a summary of the primary outcomes at baseline, visit 2 (4-6 weeks) and visit 3 (12-18 weeks). There was a statistically significant improvement in athlete knowledge $(p<0.001)$, athlete-reported use of PFT $(p<0.001)$, interdental cleaning $(p=0.013)$ and mean OSTRC score $(p<0.001)$ from baseline to visit 3 . At each visit, a different athlete recorded a very high OSTRC score, due to an acute oral health problem. Most 


\begin{tabular}{lll}
$\begin{array}{l}\text { Table } 2 \\
\text { group }\end{array}$ & Demographics and baseline oral health of the \\
\hline $\mathbf{n = 6 2}$ & Median (IQR) & Range \\
\hline Age & $24(22-27.25)$ & $18-33$ \\
& $\mathbf{N}$ & $\%$ \\
\hline Gender (male) & 44 & 71.0 \\
\hline Ethnicity (white British) & 58 & 93.5 \\
At least one tooth with moderate & 17 & 24.7 \\
decay (ICDAS $\geq 3$ ) & & 93.6 \\
Mild gum inflammation (BPE 1 or 2) & 58 & 6.5 \\
Moderate gum inflammation (BPE 3) & 4 & 46.8 \\
\hline Moderate erosion (BEWE $\geq 7)$ & 29 & \\
\hline
\end{tabular}

BEWE, Basic Erosive Wear Examination; BPE, Basic Periodontal Examination; ICDAS, International caries detection and assessment system.

non-zero scores were in the minor range $(0-30)$ and the majority of athletes scored 0 (no impact).

\section{Secondary outcomes}

The median bleeding score (table 3 ) decreased from 10 at baseline to 7.5 at visit 2 then increased to 10.5 at visit 3 . Overall there was no significant change in the bleeding score $(\mathrm{p}=0.952)$.

Fifty-eight athletes completed a written evaluation of the presentation at study visit one and 55 athletes completed an evaluation of the utility of the oral health kit at study visit three. Table 4 provides a summary of the athlete feedback. The presentation appears to have provided a good level of motivation for the athletes to adhere to the recommended oral hygiene behaviours in order to avoid negative impacts from poor oral health. In addition, most athletes intend to continue to use the PFT.

\section{DISCUSSION}

\section{Key findings}

We implemented this pragmatic, repeated measures study in three separate elite athlete groups and a high proportion $(88.7 \%)$ of athletes completed the study at 3 months despite their intensive training activities. Overall, this
Table 4 Athlete feedback provided at study visit one and study visit three

\begin{tabular}{|c|c|}
\hline \multicolumn{2}{|l|}{ Study visit 1} \\
\hline Motivators & $\begin{array}{l}\% \text { athletes motivated to } \\
\text { adhere to recommended } \\
\text { behaviour }\end{array}$ \\
\hline Impact on daily activities & 79 \\
\hline $\begin{array}{l}\text { Impact on performance in } \\
\text { sport }\end{array}$ & 88 \\
\hline $\begin{array}{l}\text { Inflammation elsewhere in } \\
\text { the body }\end{array}$ & 93 \\
\hline Unattractive appearance & 90 \\
\hline Acid erosion & 90 \\
\hline Gum diseases & 91 \\
\hline Tooth decay & 91 \\
\hline \multicolumn{2}{|l|}{ Study visit 3} \\
\hline Oral hygiene aids & $\begin{array}{l}\% \text { athletes intending to use in } \\
\text { the future }\end{array}$ \\
\hline Manual TB & 47 \\
\hline Electric TB & 65 \\
\hline PFT & 80 \\
\hline Flosspicks & 42 \\
\hline
\end{tabular}

PFT, prescription fluoride toothpaste; TB, toothbrush.

intervention was associated with improvements in athlete knowledge, enhanced oral health behaviour and athletereported performance impacts. Athletes said they were highly motivated to avoid negative impacts from poor oral health and $80 \%$ said they intended to continue to use PFT.

\section{Strengths of the study}

This study demonstrated high levels of participant retention and adherence to the intervention. We developed this study within a research framework recommended for use in the field of sports and exercise medicine; the KTS model for implementation of intervention. ${ }^{7}$ It was conducted exclusively in an elite athlete setting and

\begin{tabular}{|c|c|c|c|c|}
\hline Primary outcomes & Baseline & V2 & V3 & $P$ value \\
\hline Knowledge score median (IQR) range & $\begin{array}{l}6(5-7) \\
2-8\end{array}$ & $\begin{array}{l}7(5-8) \\
2-8\end{array}$ & $\begin{array}{l}8(6-8) \\
3-8\end{array}$ & $<0.001$ \\
\hline $\begin{array}{l}\text { Use PFT } \geq 1 \times \text { day } \\
n(\%)\end{array}$ & $8(12.9)$ & $47(79.7)$ & $45(80.4)$ & $<0.001$ \\
\hline $\begin{array}{l}\text { Clean ID } \geq 3 \times \text { week } \\
\mathrm{n}(\%)\end{array}$ & $10(16.2)$ & $30(75.0)$ & $21(34.0)$ & $=0.013$ \\
\hline OSTRC score median (IQR) range & $\begin{array}{l}0(0-8) \\
0-82\end{array}$ & $\begin{array}{l}0(0) \\
0-69\end{array}$ & $\begin{array}{l}0(0) \\
0-82\end{array}$ & $<0.001$ \\
\hline Bleeding score median (IQR) range & $\begin{array}{l}10(5-15) \\
1-36\end{array}$ & $\begin{array}{l}7.5(4-14) \\
0-51\end{array}$ & $\begin{array}{l}10.5(6.63-16) \\
0-35\end{array}$ & $=0.952$ \\
\hline
\end{tabular}

ID, interdentally; OSTRC, Oslo Sports Trauma Research Centre; PFT, prescription fluoride toothpaste. 
Table 5 Incorporating the COM-B model into the KTS

\begin{tabular}{|c|c|c|}
\hline KTS steps & Processes & Evidence/sources \\
\hline $\begin{array}{l}\text { Step } 1 \\
\text { problem } \\
\text { statement. }\end{array}$ & $\begin{array}{l}\text { Describe the problem: } \\
\text { Size of problem. } \\
\text { Severity of problem. } \\
\text { Societal burden. } \\
\text { Problem context. }\end{array}$ & $\begin{array}{l}\text { Oral health and } \\
\text { performance } \\
\text { impacts in elite and } \\
\text { professional athletes. }^{1}\end{array}$ \\
\hline $\begin{array}{l}\text { Step } 2 \\
\text { evidence } \\
\text { synthesis and } \\
\text { description. }\end{array}$ & $\begin{array}{l}\text { For all available } \\
\text { evidence: } \\
\text { Gain for the individual. } \\
\text { Gain for society. } \\
\text { Context for the } \\
\text { evidence. } \\
\text { Contemporary views. }\end{array}$ & $\begin{array}{l}\text { Oral health-related } \\
\text { behaviours reported } \\
\text { by elite and } \\
\text { professional athletes. } \\
\text { DBOH. }^{5}\end{array}$ \\
\hline $\begin{array}{l}\text { Step } 3 \\
\text { establish a } \\
\text { knowledge } \\
\text { transfer group } \\
\text { (KTG). }\end{array}$ & $\begin{array}{l}\text { Within the KTG } \\
\text { discuss: } \\
\text { KTS step 1(the } \\
\text { problem). } \\
\text { KTS step } 2 \text { (the } \\
\text { evidence). } \\
\text { Completeness and } \\
\text { representativeness of } \\
\text { the group. }\end{array}$ & $\begin{array}{l}\text { Advisory group. } \\
\text { Focus group. } \\
\text { Expert opinion. }\end{array}$ \\
\hline $\begin{array}{l}\text { Step } 4 \\
\text { intervention } \\
\text { (product) } \\
\text { development. }\end{array}$ & $\begin{array}{l}\text { Product goal. } \\
\text { Target group. } \\
\text { Product context. }\end{array}$ & COM-B model. \\
\hline $\begin{array}{l}\text { Step } 5 \\
\text { evaluation. }\end{array}$ & $\begin{array}{l}\text { Use a framework such } \\
\text { as: } \\
\text { Reach. } \\
\text { Effectiveness. } \\
\text { Adoption. } \\
\text { Implementation. } \\
\text { Maintenance. }\end{array}$ & $\begin{array}{l}\text { Study protocol. } \\
\text { Disseminate results } \\
\text { (publication) } \\
\text {. }\end{array}$ \\
\hline
\end{tabular}

COM-B, capability, opportunity, motivation and behaviour; $\mathrm{DBOH}$, delivering better oral health; KTS, knowledge transfer system.

was informed by data collected from a representative sample of Olympic and professional athletes ${ }^{14}$ to help understand the context of oral health in elite athletes. ${ }^{16}$ Our knowledge transfer group comprised behavioural change experts, dental experts and key stakeholders in elite sport including athletes and members of the support team. User engagement played a pivotal role in the development, implementation and evaluation of this project. The intervention design was based on the BCW, a contemporary behavioural change method for characterising and designing behavioural change interventions ${ }^{10}$ and the final 'product' developed using the COM-B model of behaviour that was incorporated into the KTS as an additional stage (table 5). The study, therefore, benefited from a clear and structured approach and this methodology could be applicable to other health behavioural change targets in sports medicine.

In relation to oral health the preventive interventions conformed with best available evidence contained in the guidance, Delivering Better Oral Health. ${ }^{5}$

Oral health promotion by dental professionals has been shown to have a positive effect on recipient knowledge, behaviour and gingival health. ${ }^{17}$ Therefore the $10 \mathrm{~min}$ presentation was delivered by a dentist (JG) and the three short (90s) information films featured an Olympic athlete as a model. Information included the following elements: emphasise the benefits of adherence to the recommended oral hygiene routine, provide information on susceptibility to oral disease, encourage athlete to plan where, when and how the behaviour will occur and emphasise habit formation. During the oral health screening, feedback to each athlete provided a further opportunity to enhance motivation by emphasising cognitions likely to increase the recommended behaviour. ${ }^{18}$

The baseline oral health score for the athlete groups in this study were lower than the levels of oral diseases measured in our previous epidemiological study. ${ }^{1}$ The reason for this is not clear, however, we were not able to conduct representative sampling due to the requirements of this study and availability of athletes. The lower levels of disease could be a random chance phenomenon or reflect selective bias if more athletes with better oral health volunteered.

\section{Limitations of the study}

There were, however, some limitations to this study, the most important being the lack of a control group. We had originally planned for a randomised controlled trial, but teams did not wish to involve athletes in a control group. Coaches and elite team managers did not consider attendance for repeated monitoring of a non-intervention group an appropriate use of athletes' time. Another is the reliance for several of the outcome measures on self-report.

Blinding of the examiner or the participants was not possible. Like many behavioural change interventions, there was a short-term improvement in knowledge and behaviours but no measurable health outcome changes. This study employed a number of elements and future research could aim to identify which are most effective from an athlete perspective. The intervention in this study was aimed at the whole group. Future research could further investigate the use of specific behavioural change techniques during feedback to individual athletes. This was a short-term study, conducted with limited resources, however, it provides a basis for a larger scale implementation initiative.

\section{Implications for well-being and performance}

In elite sport, performance is everything ${ }^{16}$ and there can be differences in perspective between a performance point of view and a medical viewpoint. ${ }^{19}{ }^{20}$ High-performance sport is a time-pressured environment where immediate results can often supersede pursuit of the most effective evidencebased practice. ${ }^{21}$ We hypothesised that 'loss aversion' would be a more potent motivator (' $\mathrm{M}$ ' from COM-B) than oral health improvement. The intervention was designed to target this aspect as well as another target which became apparent during the initial athlete engagement phase, that is, appearance. We conducted a poststudy evaluation which found that the factor which was most widely reported to have 
motivated the athletes $(93 \%)$ to adhere to the intervention was avoidance of inflammation from oral disease elsewhere in the body. The use of short $(10 \mathrm{~min})$ intervention strands seemed most implementable in high-performance sport as they have been used widely for lifestyle interventions such as tobacco cessation. Elite athletes are a highly disciplined group and this intervention built on established oral healthcare routines, requiring little additional behavioural change from the athletes, demonstrating similarity with other models that place emphasis on an intervention being easy, attractive, social and timely. This study demonstrates that The KTS plus the BCW provides a framework on which to base future implementation research.

\section{CONCLUSIONS}

This study demonstrates that an oral health intervention, based on contemporary behavioural change theory (COM-B model of behaviour) implemented in three separate groups of elite athletes, was associated with good adherence and improvements in athlete oral health knowledge, enhanced oral health behaviour, reduced performance impacts and high participant retention. Short $(10 \mathrm{~min})$ educational interventions with provision of PFT and interdental cleaning aids to mitigate the risks of dental caries and periodontal diseases are simple interventions that appear to be well accepted by elite athletes.

Twitter Julie Gallagher @oralhealthsport and lan Needleman @lanNeedleman

Acknowledgements We wish to acknowledge the willing participation of all athletes and support staff. We appreciate the valuable guidance from Professor Susan Michie, Professor Robert West and Artur Direito at UCL Centre for Behaviour Change. Thank you to Ms Haifa Qadees for data entry.

Contributors JG was responsible for the first and final draft. PA and IN reviewed and contributed to the final draft. JG, PA and IN contributed to the study design. JG collected and analysed the study data.

Funding This study was funded by a BASEM research bursary. JG is a PhD candidate, supported by a joint award from GSK and UCL IMPACT. The Brushlink devices were provided free of charge.

Competing interests The Centre for Oral Health and Performance is part of the UK IOC Research Centre for Prevention of Injury and Protection of Athlete Health with the Institute of Sport Exercise and Health (ISEH) and the National Centre for Sport and Exercise Medicine (NCSEM).

Patient and public involvement Patients and/or the public were involved in the design, or conduct, or reporting, or dissemination plans of this research. Refer to the Methods section for further details.

Patient consent for publication Not required.

Ethics approval We received ethical approval from UCL Research Ethics Committee Chair's approval (Project ID 6388/002).

Provenance and peer review Not commissioned; externally peer reviewed.

Data availability statement All data relevant to the study are included in the article or uploaded as supplementary information. The full study protocol and additional deidentified participant data including additional secondary outcomes is available on request from the corresponding author. The intervention short films can be viewed at https://www.ucl.ac.uk/eastman/centre-oral-health-andperformance.

Open access This is an open access article distributed in accordance with the Creative Commons Attribution Non Commercial (CC BY-NC 4.0) license, which permits others to distribute, remix, adapt, build upon this work non-commercially, and license their derivative works on different terms, provided the original work is properly cited, appropriate credit is given, any changes made indicated, and the use is non-commercial. See: http://creativecommons.org/licenses/by-nc/4.0/.
ORCID iDs

Julie Gallagher http://orcid.org/0000-0003-4891-738X

Paul Ashley http://orcid.org/0000-0003-0312-5311

lan Needleman http://orcid.org/0000-0003-4696-1651

\section{REFERENCES}

1 Gallagher J, Ashley P, Petrie A, et al. Oral health and performance impacts in elite and professional athletes. Community Dent Oral Epidemiol 2018;46:563-8.

2 Needleman I, Ashley P, Petrie A, et al. Oral health and impact on performance of athletes participating in the London 2012 Olympic games: a cross-sectional study. Br J Sports Med 2013;47:1054-8.

3 Needleman I, Ashley P, Meehan L, et al. Poor oral health including active caries in 187 UK professional male football players: clinical dental examination performed by dentists. $\mathrm{Br} J$ Sports Med 2016;50:41-4.

4 Gallagher J, Ashley P, Petrie A, et al. Oral health-related behaviours reported by elite and professional athletes. Br Dent $J$ 2019;227:276-80.

5 Department of Health. Public health England. delivering better oral health: an evidence-based toolkit for prevention third edition London, 2017. Available: www.gov.uk/government/publications/ delivering-better-oral-health-an-evidence-based-toolkit-forprevention [Accessed 18th Jan 2018].

6 Finch CF, Talpey S, Bradshaw A, et al. Research priorities of international sporting federations and the IOC research centres. BMJ Open Sport Exerc Med 2016;2:e000168.

7 Verhagen E, Voogt N, Bruinsma A, et al. A knowledge transfer scheme to bridge the gap between science and practice: an integration of existing research frameworks into a tool for practice. Br J Sports Med 2014:48:698-701.

8 Matheson GO, Klügl M, Engebretsen L, et al. Prevention and management of non-communicable disease: the IOC consensus statement, Lausanne 2013. Br J Sports Med 2013;47:1003-11.

9 Michie S, Atkins L, West R. The behaviour change wheel : a guide to designing interventions. Great Britain: Silverback Publishing, 2014.

10 Michie S, van Stralen MM, West R. The behaviour change wheel: a new method for characterising and designing behaviour change interventions. Implement Sci 2011;6:42.

11 Jepsen S, Blanco J, Buchalla W, et al. Prevention and control of dental caries and periodontal diseases at individual and population level: consensus report of group 3 of joint EFP/ORCA workshop on the boundaries between caries and periodontal diseases. J Clin Periodontol 2017;44:S85-93.

12 Richards W, Filipponi T, Roberts-Burt V. Mind the gap! a comparison of oral health knowledge between dental, healthcare professionals and the public. Br Dent J 2014;216:E7

13 Clarsen B, Myklebust G, Bahr R. Development and validation of a new method for the registration of overuse injuries in sports injury epidemiology: the Oslo sports trauma research centre (OSTRC) overuse injury questionnaire. Br J Sports Med 2013;47:495-502.

14 Gallagher J, Needleman I, Ashley P, et al. Self-Reported outcome measures of the impact of injury and illness on athlete performance: a systematic review. Sports Med 2017;47:1335-48.

15 Mokkink LB, Terwee CB, Patrick DL, et al. The COSMIN checklist for assessing the methodological quality of studies on measurement properties of health status measurement instruments: an international Delphi study. Qual Life Res 2010;19:539-49.

16 Bolling C, van Mechelen W, Pasman HR, et al. Context Matters: Revisiting the First Step of the 'Sequence of Prevention' of Sports Injuries. Sports Med 2018;48:2227-34.

17 Kay E, Vascott D, Hocking A, et al. A review of approaches for dental practice teams for promoting oral health. Community Dent Oral Epidemiol 2016;44:313-30.

18 Newton JT, Asimakopoulou K. Minimally invasive dentistry: enhancing oral health related behaviour through behaviour change techniques. Br Dent J 2017;223:147-50.

19 Levy D, Delaney JS. A risk/tolerance approach to the preparticipation examination. Clin J Sport Med 2012;22:309-10.

20 Dijkstra HP, Pollock N, Chakraverty R, et al. Managing the health of the elite athlete: a new integrated performance health management and coaching model. Br J Sports Med 2014;48:523-31.

21 Costello N, McKenna J, Sutton L, et al. Using contemporary behavior change science to design and implement an effective nutritional intervention within professional rugby League. Int $J$ Sport Nutr Exerc Metab 2018;28:553-7. 